\title{
Optimization and Simulation of Boiler Water Level Control Based on the Fuzzy Neural Network
}

\author{
Zhimin $\mathrm{Yu}^{1 *}$, Long Cheng ${ }^{2}$, Zhenyong $\mathrm{Hao}^{3}$ and Renzhong Wang ${ }^{4}$ \\ ${ }^{1}$ Tianjin maritime college. 300350 .China \\ ${ }^{2}$ Tianjin Maritime Safety Administration .300351.China \\ ${ }^{3}$ China Oilfield Services Limited 300351.China \\ ${ }^{4}$ School of ocean Yan tai University.264000.China \\ *Corresponding author
}

\begin{abstract}
Objective] To adjust the parameter PID of boiler water level control.Analysis of the problems existing in the Marine boiler water level control.[Method] Using fuzzy neural network, Fuzzy neural network is the combination of neural network and fuzzy logic. the traditional PID control and fuzzy neural network control modeling, simulation comparison.[Result] The results show that the fuzzy neural network control convergence is good, the method is effective.[Conclusion] The conclusion is of reference significance to improve boiler water level control.
\end{abstract}

Keywords-boiler water level control; fuzzy logic;fuzzy neural network $g ;$ PID

\section{INTRODUCTION}

The boiler can be used to produce steam heating ship fuel oil system. Some ship can use steam to drive a turbine power generation, can use steam to drive a tanker cargo oil pump and ballast pump. Boiler is an important equipment of ship. The generation of steam to automatically adjust the water level, water level of boiler automatic control is to maintain the normal level. It is through the control of feed water pump startup (feed valve opening) to control the boiler feed water, feed water and evaporation balance to ensure the normal operation of boiler. If the steam boiler water level is too high humidity.impact drive equipment.The evaporation capacity of the boiler equipment and peripheral equipment load demand at any time, when steam need large, steam drum water level changes quickly, if the crew do not pay attention to. It will be easy to burn caused by false level even dry pot, or drum filled with water. Water level directly affects the separation speed and the quality of the production of steam, boiler water level is one of the important parameters to ensure the ship's safe. At present, the boiler water level control often use PID controller. The PID parameter proportion with integral and differential time setting affect the level of control performance.Parameter setting for the crew is difficult.Proportional and integral differential time adjust will take great effort, adjustment effect is not ideal. Therefore, the best boiler water level control can realize intelligent, PID parameters according to the outside changes and automatic setting. Boiler feed water system of boiler feed pump, the pump pressure is constant, the water level sensor sensing water level change signal to the controller. The controller is computing. Output signal control the feed valve opening. By changing the feed valve regulate the boiler water level.

\section{PID FuZzY CONTROLlER B ASED ON NEURAL NETWORK}

Fuzzy controller is the biggest advantage is not dependent on the controlled object accurate mathematical model, and prone to prevent oscillation stability with super sex, control attenuation and control overshoot.The fuzzy controller is suited to solve the problems ofthe marine boiler water level control.In the digital control system, PID control algorithm is usually written in incremental form, mathematical formula such as (1)

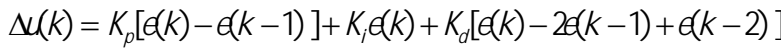

Formula (1), $\mathrm{Kp}$ is proportional coefficient, $\mathrm{Ki}$ is integral coefficient, $\mathrm{Kd}$ is differential coefficient. In traditional PID control, in order to get good control effect. Adjust the appropriate proportion of $\mathrm{Kp}, \mathrm{Ki}$ and then to eliminate static error integral time must be appropriate. Small strong dynamic process caused by vibration of the system is not stable. The appropriate differential time $\mathrm{Kd}$ is considering water mutation regulation in advance, $\mathrm{Kp}, \mathrm{Ki}, \mathrm{Kd}$, and the size of the three interrelated, interaction and regulation methods experienced method.This method requires adjusting personnel have rich practical experience, have attenuation curve method is to utilize damping ratios to control dynamic process.In particular the boiler feed water system certainly exist the optimal $\mathrm{Kp}, \mathrm{Ki}, \mathrm{Kd}$ values, because with a particular learning algorithm of neural network can take advantage of the neural network to find some kind of nonlinear combination of the optimal control law. To implement the boiler water level control tasks.Marine boiler water level control of the neural network fuzzy control system is controlled by the input link.Boiler water level and the operation including traditional PID controller of fuzzy quantitative link.The outside changes simulated learning algorithm and water level on the fuzzy quantitative.The actual water level change learning algorithm to gain recognition network NN1,NN2 provide the necessary information. Identify network mainly in order to establish the identification model of boiler water level control system, a neural network on-line modification. The controlled formation of the closed loop control system. Fuzzy quantitative module, equivalent to NN2 preprocessing of the neural network input.The network NN2 output characteristic of the boiler control variable $\mathrm{K}_{\mathrm{p}}$ (ratio), $\mathrm{K}_{\mathrm{i}}$ 
(integral coefficient), $\mathrm{K}_{\mathrm{d}}$, (differential coefficient). as shown in figure 1 of fuzzy control system based on neural network structure. Implementation method of PID algorithm. uses the five-step method specific as follows.

Step1: y (k) is obtained by sampling and $\mathrm{r}(\mathrm{k})$, and then calculate $\mathrm{e}(\mathrm{k})=\mathrm{r}(\mathrm{k})-\mathrm{y}(\mathrm{k})$ Step 2: After the normalization processing will e $(\mathrm{k})$ fuzzy quantification.According to the actual water boiler and boiler water level deviation given to the size..

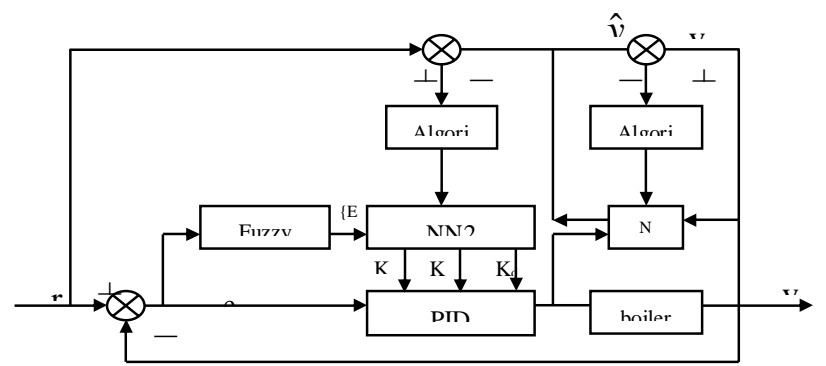

FIGURE I. THE FUZZY CONTROL SYSTEM BASED ON NEURAL NETWORK STRUCTURE

such as formula (2), namely deviation with the given value than the absolute value of less than 0.03 and greater than 0.03 is less than 0.1 , is greater than 0.1 is less than 0.3 , is greater than 0.3 is less than 0.5 , is greater than 0.5 shown in five files. Archive process is deviation with the given value than the scope of the absolute value of also to fuzzy quantitative e (k).

$$
E=\left\{\begin{array}{ll}
4 \operatorname{sign}(e) & |e / r| \geq 0.5 \\
3 \operatorname{sign}(e) & |e / r| \geq 0.3 \\
2 \operatorname{sign}(e) & |e / r| \geq 0.1 \\
1 \operatorname{sign}(e) & |e / r| \geq 0.03 \\
0 \operatorname{sign}(e) & |e / r|<0.03
\end{array}\right\}
$$

Formula (2) sign (*) symbol function, function are the three conditions such as type of (3)

$$
\operatorname{sign}(x)= \begin{cases}1 & x>0 \\ 0 & x=0 \\ -1 & x<0\end{cases}
$$

Step 3: Identify network NN1 created.Set according to the actual of boiler water level and water level is (4) output nonlinear function and learning algorithm such as formula.

$$
y(k)=f[y(k-1), \cdots, y(k-n), u(k-1), \cdots u(k-m)]
$$

the formula(4) $(\mathrm{f} * * * *)$ is a nonlinear function, $\mathrm{y}$ is the input signal, $\mathrm{u}$ is the output signal, $\mathrm{n}$ is the order time $\{\mathrm{y}(\mathrm{k})\}$, $\mathrm{m}$ is the order of $\{\mathrm{u}(\mathrm{k})\}$. Neural network layer such as formula such as(5)

$$
\begin{aligned}
& O_{i}^{(I)}(k)= \begin{cases}y(k-i) & 0 \leq i \leq n-1 \\
u(k-i+m) & n \leq i \leq n+m-1\end{cases} \\
& O_{(n+m)}^{(I)}(k)=1
\end{aligned}
$$

Formula as an object of the neural network input layer in (5)after a delay of output y (k - I) and u (k - I).The time sequence $\{\mathrm{y}(\mathrm{k})\}$ and $\{\mathrm{u}(\mathrm{k})\}$ as the model feature The hidden layer neural network such as formula(6)

$$
\begin{aligned}
& I_{j}^{(h)}=\sum_{i=0}^{n+m} V_{j i} O_{i}^{(l)} \quad j=0,1, \cdots, R-1 \\
& O_{j}^{(h)}(k)=f\left[I_{j}^{(h)}(k)\right] \quad O_{R}^{(h)}=1
\end{aligned}
$$

\{Vji\} in equation (6) is hidden layer weights; $\mathrm{Vj}(\mathrm{n}+\mathrm{m})$ is a threshold value; $F(x)$ is the activation functions.Superscript (I) is input layer, superscript (h), respectively is the hidden layer. The neural network output layer such as (7)

$$
\hat{y}(k+1)=\sum_{j=0}^{R} W_{j} O_{j}^{(h)}(k)
$$

$\{\mathrm{Wj}\}$ in the formula 1.7 is output layer weight function, weight function is a linear function, through the neural network learning algorithm to modify the $\mathrm{j}(\mathrm{n}+\mathrm{m})$ (threshold). The function $J_{I}=\frac{1}{2} \sum_{p}[y(k+1)-\hat{y}(k+1)]^{2}$ minimum.Available for corresponding correction formula :(8) and (9)

$$
\begin{aligned}
& \Delta W_{j}(k+1)=\alpha[y(k+1)-\hat{y}(k+1)] O_{j}^{(h)}(k)+\beta \Delta W_{j}(k) \\
& \Delta V_{j i}(k+1)=\alpha[y(k+1)-\hat{y}(k+1)] f^{\prime}\left(I_{j}^{(h)}(k)\right) W_{j}(k) O_{i}^{(I)}(k)+\beta \Delta V_{j i}(k)
\end{aligned}
$$

In order to accelerate the convergence study, take the maximum efficiency. In order to avoid the oscillation of the learning can be adjusted by the gradient of inertia coefficient, the formula (8), (9) the value of alpha, beta, in the selection on $[0,1]$, alpha vector is, rate of beta is inertia.

Step 4: The establishment of the neural network NN2, usable $\mathrm{G}(* * *)$ to describe the output of the PID, such as the formula $(10)$

$$
u(k)=G\left[u(k-1), K_{P}, K_{i}, K_{d}, e(k), e(k-1), e(k-2)\right]
$$

In the formula $(10) \mathrm{G}(*)$ is a nonlinear function, and the nonlinear function, $y(\mathrm{k})$.Using neural network NN2 through training and learning to find an optimal control. The input of the network NN2 is after dealing with the blur of system state variables, and neural network NN2 input and output of each layer neurons using three layer BP network as shown in figure 2.The network has the input node $S, S$ for the number of input variable, depending on the complexity of the controlled object.The input node to simulate the shaking, work status and ship consume a large amount of steam and produce the switch state suchas soda boiling boiler. Hidden layer nodes for $\mathrm{H}, \mathrm{H}$ is 3 the three output node for the proportion of the PID controller 
coefficient differential coefficient and integral coefficient. The hyperbolic tangent function as formula (11)

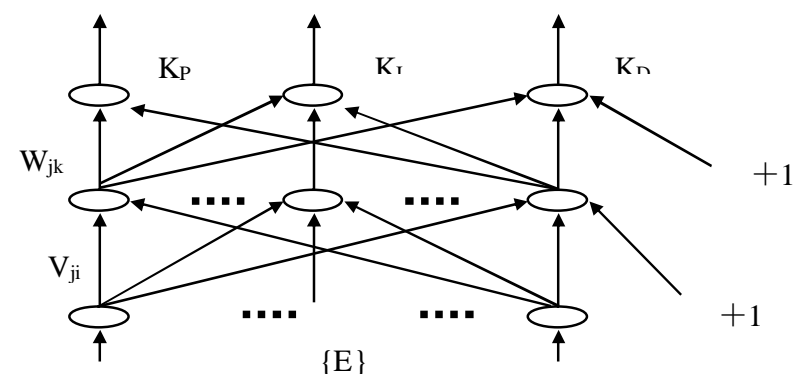

FIGURE II. NN2 NEURAL NETWORK STRUCTURE

$$
I_{j}^{(2)}(k)=\sum_{i=0}^{S} V_{j i} O_{i}^{(1)}(k) \quad O_{j}^{(2)}(k)=f\left[I_{j}^{(2)}(k)\right] \quad j=0,1, \cdots, H-1 \quad O_{H}^{2)}=1
$$

In the formula $(11), \mathrm{f}(* * *)$ as the hyperbolic tangent type activation function. Superscript (1) is the input layer.Superscript (2) is hidden layer.Superscript (3) the output layer, $\{\mathrm{Vji}\}$ is hidden layer weights, Vjs is the threshold.

Step 5: The output of the traditional PID controller to adjust the opening of the boiler feed water valve,At the same time signal input identification network NN1, classics, cycle study and calculation. The final output optimal Kp (ratio), Ki (integral coefficient), Kd, (differential coefficient). As shown Figure3 Neural network design parameter simulink settings, and Figure4 Neural network simulink design program.

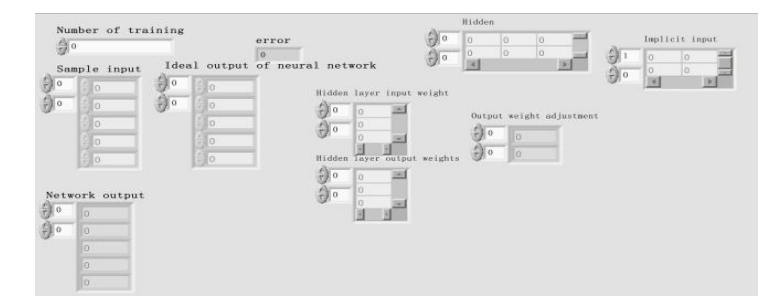

FIGURE III. NEURAL NETWORK SIMULINK DESIGN PARAMETER SETTINGS

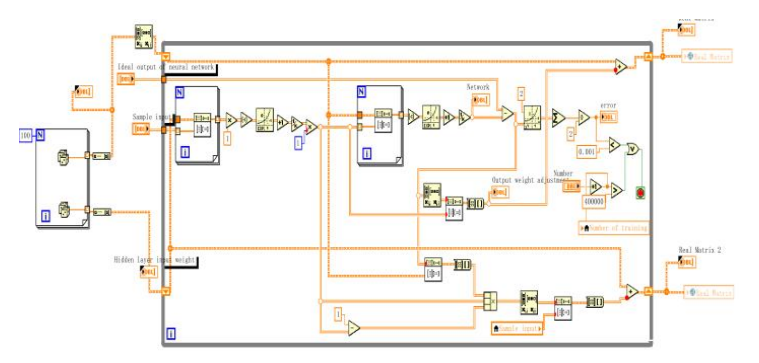

FIGURE IV. NEURAL NETWORK SIMULINK PROGRAM

\section{SimUlation IMPLEMENTATION OF FUZZY CONTROLLER}

Simulation implementation, based on the fuzzy controller is combined with the cycle of neural network learning features.Automatic intelligent adjustment $\mathrm{Kp} \mathrm{(ratio),} \mathrm{Ki} \mathrm{(} \mathrm{integral} \mathrm{coefficient),} \mathrm{Kd} \mathrm{,} \mathrm{(differential}$ coefficient). Through the simulation model, Use Simulink simulatiion and the design of the fuzzy controller, called the designed fuzzy controller file gishui. Fis.The design of the neural network fuzzy PID control system based on vi files as shown in figure 1.3.Validation is more superior to traditional PID control.Fuzzy control according to water level fuzzy control principle diagram, detailed simulation design the following steps:

First step :Simulink boiler feed water system, through the step input on behalf of the boiler water level change.The actual deviation quantitative factor is 0.06 .The differential quantization factor is 0.3 quantitative factor is derived from the neural network output.After the operation to the input of the fuzzy controller.The fuzzy controller output, considering the outside change impact factor is 1.2 , as shown in figure 4.The actual water level of the transfer function can be expressed as $\mathrm{G}(\mathrm{s})=\mathrm{H}(\mathrm{s}) / \mathrm{W}(\mathrm{s})=\mathrm{K} /(\mathrm{Ts} 2+\mathrm{s})[10]$. The formula of the $\mathrm{H}$ for the current water level, $\mathrm{W}$ for the current water flow, for feed water flow under the disturbance of the coefficient, KT boiler feed water system for inertial time constant. $\mathrm{K}$ values range from 0.02to 0.06.database, and provide data for reasoning machine. Rule base is used to store the fuzzy control method and the reasoning of the reasoning machine.Provides control law is based on the shipyard debugging expert knowledge and shipping line chief engineer and engineers such as long-term accumulation of experience.The advantages of the reasoning machine language representation is a kind of intuitive reasoning. Boiler water level fuzzy controller, the system input variables to set the water level and the actual water level deviation .The output of the opening of the regulating valve control signal , corresponding linguistic variables respectively e, EC and u, fuzzy rules can be simple language, for example (if e () set the water level and the actual water level deviation is big then $u$ (output of the opening of the regulating valve control signal) is negative).Meaning the rules is high water levels rise faster, level control valve signal that rapidly falling water levels). The fuzzy inference machine is based on the input amount and completed database, rule base, fuzzy inference, and solve the fuzzy relation equations such as (12)

$$
U=(E \times E C) \cdot R
$$

In the formula(12), symbol "."on behalf of the quantity of fuzzy synthetic operation. Symbol "x" on behalf of the direct product of fuzzy quantity calculations; "R" represent the fuzzy relationship between symbols.

For accurate control of boiler water level fuzzy quantity must be converted into precise volume.It can only accept a control volume of the object, and their interfaces are the fuzzy decision by fuzzy inference machine output into a precise amount. Using Matlab fuzzy logic editor, fuzzy logic editor is a graphical system design tool.Matlab fuzzy control toolbox is the design of fuzzy controller is very convenient, only need to set the corresponding parameter.Quickly get fuzzy control, convenient and modify the parameters. The fuzzy controller using Matlab toolbox in Matlab command window, enter the fuzzy, click enter the keyboard as shown in figure 5 


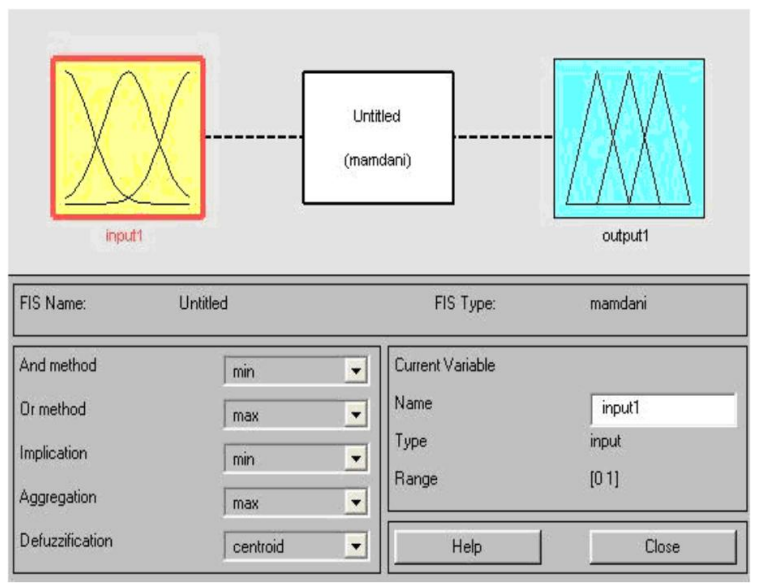

FIGURE V. THE ESTABLISHMENT OF THE FUZZY CONTROLLER

Determine the description of language input and output variables of the fuzzy subset of PB (board) - take +6 nearby.PM (middle) - take near + 4.PS is (small) - take near + 2.0 (zero) - take near zero. NS (negative) - take a near - 2. NM (negative) - take a near - 4.NB (negative) - take near - 6.Add the membership function $\mathrm{E}$ theory of domain in the range of [3 of 3]. So you need to add 7 membership function, and set up the theory of input and output variables of a domain. E setting error, error of EC change, $U$ control domain.Select the corresponding membership function fuzzy linguistic variables. Using the toolbox Member Function Edit, open Member Function Edit window. As shown in figure 6, according to the fuzzy control rules establish logical relationship will build good FIS editor is saved as a file.(gishui.fis.)

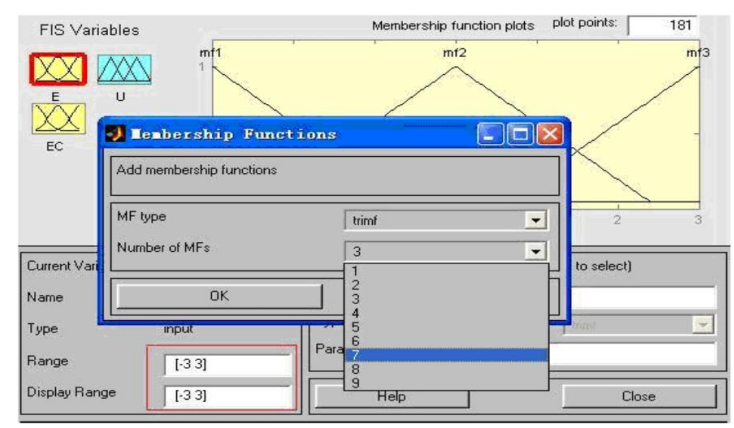

FIGURE VI. FUZZY CONTROLLER LOGIC RELATION.

The third step in Simulink, the fuzzy control module to invoke the designed fuzzy controller file gishui. Fis, and before the simulation gishui. Fis read in work space, the simulation result is when the control object input and system step response curve. Based on the dynamic response of the neural network fuzzy PID adaptive control is shown in figure 7(a). The dynamic response of the traditional PID control as shown in figure 7(b)

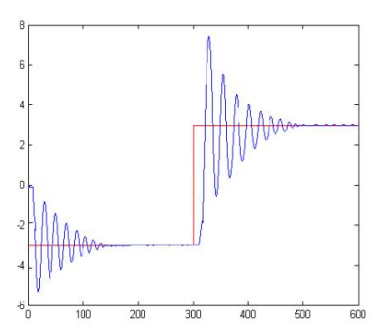

(a)

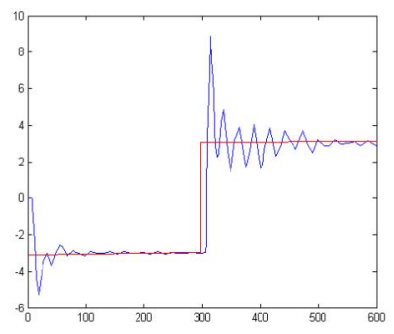

(b)
FIGURE VII. (A) BASED ON THE DYNAMIC RESPONSE OF THE NEURAL NETWORK FUZZY PID ADAPTIVE CONTROL ;(B)THE DYNAMIC RESPONSE OF THE TRADITIONAL PID CONTROL

Boiler feed water system simulation model based on fuzzy algorithm and the traditional PID controller and fuzzy control system simulation. Boiler water levelsystem step response output in figure 1.6 and figure 1.7.We can drive the PID dynamic deviation, oscillation frequency, low boiler water level control precision, poor ability to adapt to changes in the outside world. Improving design of fuzzy PID neural network greatly reduces the boiler water level dynamic deviation, effectively restrain oscillation in the process of boiler control,Avoid the boiler water level adjustment in advance, for boiler water level control is more precise, the static deviation decreases. Improve the boiler water level according to the change of adaptive performance is greatly improved.in short.The neural network fuzzy PID easy stability with super prevent oscillation attenuation, control, control overshoot.

\section{CONCLUSION}

Using Matlab toolbox Member Function fuzzy controller design. Edit realize simulation of boiler feed water control based on fuzzy controller.

Neural network output optimal Kp (ratio), Ki (integral coefficient), $\mathrm{Kd}$, (differential coefficient).The intelligence of parameter modification, in the simulation can modify the parameters of the object. It can modify the membership functions and control rules and quantitative theory domain, input and output of language variable.

Boiler water supply system based on fuzzy algorithm is compared with the traditional PID control simulation analysis. Fuzzy algorithm of boiler feed water system stability with super more easily prevent oscillation attenuation, control, control overshoot.

From the point of the simulation results. The boiler feed water system based on fuzzy algorithm is better than traditional control performance of PID control. The boiler feed water system control based on fuzzy algorithm has very good ability to adapt to environmental changes and self-learning ability of automatic intelligent modifying PID proportion, integral and differential time. When a ship is the outside changes, has the very good control performance. 


\section{REFERENCES}

[1] Guo Linjie. Large oil tankers for auxiliary boiler system modeling and simulation study [D]; Dalian maritime university; 2013,

[2] Xiao-dan liu. Based on RBF fuzzy neural network of Marine boiler steam drum water level control research [D]. Dalian maritime university; 2008 ,

[3] Li Sijun. No media research and realization of the hardware-in-the-loop simulation system [D]. Tianjin university of science and technology; 2009

[4] FeiJingZhou.Based on generalized predictive control of Marine boiler steam drum water level control research [D]. Harbin engineering university; 2008

[5] Sun Bing. Simulation of a Marine auxiliary boiler fuel oil system based on VB [D]. Dalian maritime university; 2008

[6] Qiu Dabao. Large oil tanker auxiliary boiler system simulator development [D]. Dalian maritime university; 2012

[7] WANG Yang.Multi-model Predictive Control of Drum Water Level Based on RBF Neural Network Dynamic Compensation [J]. ShipScienceandTechnology, 2017, (02): 52-54

[8] YU Zhimin.Optimal and Control Simulation of Ship Boiler Based on Fuzzy Neural Network [J] . Journal of Tianjin Vocational Institutes, 2017, (04): 116-122 + 128

[9] CHEN Wen-xing, XUE Shi-long, SUN Lei, ZHANG Ya-ming.Modeling and monitoring of water level control system based on PLC boiler boiler [J]. Journal of Shanghai Dianji University, 2017, (02): 98-102

[10] WANG Zha-xia, WANG Lin-jin, FANG Yong. Detection and control of liquid level in drum boiler [J]. PetroChina, 2017, (05): 138-139

[11] ZHONG Qi-sheng.NAKAKITA NS778AN Type Water Level Automatic Control Failure Failure and Its Elimination Method [J]. PearlRiverWaterTransport, 2017, (11): 90-91. 